\title{
$\mathrm{SO}_{2}$ 诱导的毛白杨叶片 LCL 发射光谱变化 ${ }^{*}$
}

马玉琴 张仲纶 苏 震 郑雁珍
马 斌 刘成祥 赵克俭

(中国科学院生物物理研究所, 北京 100101)

\section{王英彦 王继光}

(北京环境保护科学研究所, 北京 100037)

\section{关链词毛白杨叶片、低水平化学发光、发射光徣}

二氧化硫是大气主要污染物. 植物对 $\mathrm{SO}_{2}$ 反应十分敏感, 通常人和动物还不致引起伤害 的污染剂量, 却可使一些植物受到伤害 ${ }^{[1]}$. 叶片是植物进行气体交换的器官, 庞大的叶表面与 空气接触使 $\mathrm{SO}_{2}$ 得以随着空气一起通过气孔进人叶内. 所以, $\mathrm{SO}_{2}$ 的伤害首先表现在叶片上. 余叔文等人 ${ }^{[23]}$ 的研究指出: “当急性伤害症状出现时, 阔叶植物叶片脉间有不规则形坏死斑, 斑点大小不一或呈块状”, “受 $\mathrm{SO}_{2}$ 伤害的叶片有的能发特殊的荧光”, 并认为这是一种可以 利用的特性. 因此, 利用植物叶片发光表征 $\mathrm{SO}_{2}$ 污染日益受到人们的重视 ${ }^{[4]}$. 直接利用叶片 本身自发的低水平化学发光, 可不经过任何物理的的或化学方法处理, 度量出 $\mathrm{SO}_{2}$ 污染, 这是 一种真实可信又简便的方法. 本文作者 ${ }^{[9]}$ 用人工熏气实验发现毛白杨叶片的发光与 $\mathrm{SO}_{2}$ 的浓 度相关. 这些研究虽然使利用植物指示大气污染的工作迈进了一步, 但还不能将 $\mathrm{SO}_{2}$ 的单一 作用从复杂的气态环境中识别出来. 从理论上, 生物活体的 LCL 是与机体的能量代谢、氧化 代谢和毒性效应有关. 它是在正常的生理和特定病理过程中发出的微光. 无疑, $\mathrm{SO}_{2}$ 伤害的 结果必然会导致叶片发光规律的变化, 尤其是特征的发射光谱的改变. 该研究是前一研究的 补充和延续, 以期尽早将这一崭新的生物物理指标用于实践.

\section{1 材 料 和 方 法}

\section{1 叶片采集}

在毛白杨树上选取适宜的枝条进行 $\mathrm{SO}_{2}$ 熏气实验, 详尽方法见文献[5]. 测量时取枝条上 中位叶之间的叶片, 要求叶面大小类同. 实验于 $6-7$ 月间进行, 清晨 $7-9$ 点采样 $\left(25-35^{\circ} \mathrm{C}\right.$, 湿度 $80 \%$ 左右), 叶片放人样品室直接测量.

\section{2 材料}

$\mathrm{SO}_{2}, \mathrm{NO}$ 和 $\mathrm{CO}$ 均为国家标准气体.

\section{3 发射光谱分析}

波长为 $400-800 \mathrm{~nm}$ 的一套干涉滤光片, 间隔 $15-20 \mathrm{~nm}$. LCL 发射光谱分析使用 BPCL 型微弱发光测量仪, 见文献[5].

1993-06-22 收稿, 1993-10-08 收修改稿.

*国家自然科学基金资助项目。 


\section{2 实 验 结 果}

\section{1 经 $2 \% \mathrm{SO}_{2}$ 需气 $1 \mathrm{~h}$ 后毛白杨叶片 LCL 发射光谱的变化}

考虑叶片发射光谱分析精确性, 实验在高浓度 $\mathrm{SO}_{2}(2 \%)$ 所导致的叶片急性伤害条件下进 行. 这时被 $\mathrm{SO}_{2}$ 熏气过的叶片已出现常见的急 性伤害症状, 叶片 LCL 发光值急剧上升. 此时 发射光谱的变化如图 1 所示. 由图可见, 在正常 生理条件下 (图 1 (a)) 毛白杨叶片的 LCL 发射光 谱近似为一条 Gaussion 分布曲线. 光子发射主要 分布在 $620-780 \mathrm{~nm}$ 的红光及红外光区, 占总发 光强度 $80 \%$ 以上, 最大光峰为 $710 \mathrm{~nm} .475 \mathrm{~nm}$ 和 $535 \mathrm{~nm}$ 还有 2 个小光峰. $2 \% \mathrm{SO}_{2}$ 熏气后呈现一条 多峰曲线 (图 1(b)). 最大光峰仍坐落在 $710 \mathrm{~nm}$ 处, 同时在 595,660 和 $760 \mathrm{~nm}$ 有 3 个分解的光 峰. 除此而外, 谱分布蓝移使 $475 \mathrm{~nm}$ 的发光强度 增加近 4 倍. 显示出 $\mathrm{SO}_{2}$ 急性伤害毛白杨叶片发 射光谱的特征性变化.

\section{$2.2 \mathrm{CO}$ 和 NO 对毛白杨叶片发射光谱的作用}

$\mathrm{CO}$ 常伴随着燃煤过程释放到大气, 是构成大 气污染的又一重要污染物. 当用相同浓度 CO 以 相同方法熏气毛白杨叶片后 (图 2(a)), 叶片的 LCL

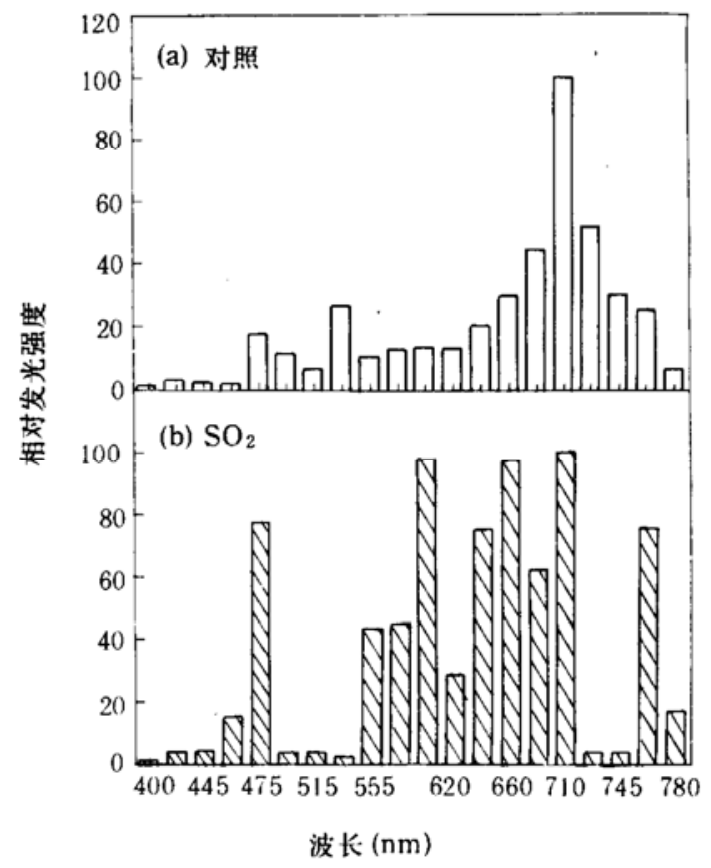

图 $1 \mathrm{SO}_{2}$ 诱发的毛白杨叶片 LCL 发射光谱 (a) 对照 (未熏气), (b) $\mathrm{SO}_{2}$ 熏气后 发射光谱像对照组叶片谱形一样, 成 Gaussion 分布; 但在 $660 \mathrm{~nm}$ 处的发光强度有较明显变 化, 未发现谱分布蓝移现象. 氮的氧化物 $\left(\mathrm{NO}_{x}\right)$ 包括 $\mathrm{NO}_{2}, \mathrm{NO}$ 及 $\mathrm{N}_{2} \mathrm{O}$ 等多种化合物, 能渗透 叶片的角质层使树木损伤. 但它的毒性只有 $\mathrm{SO}_{2}$ 的 $1 / 10$ 左右, 属光化学反应物质. 由于 $\mathrm{NO}$

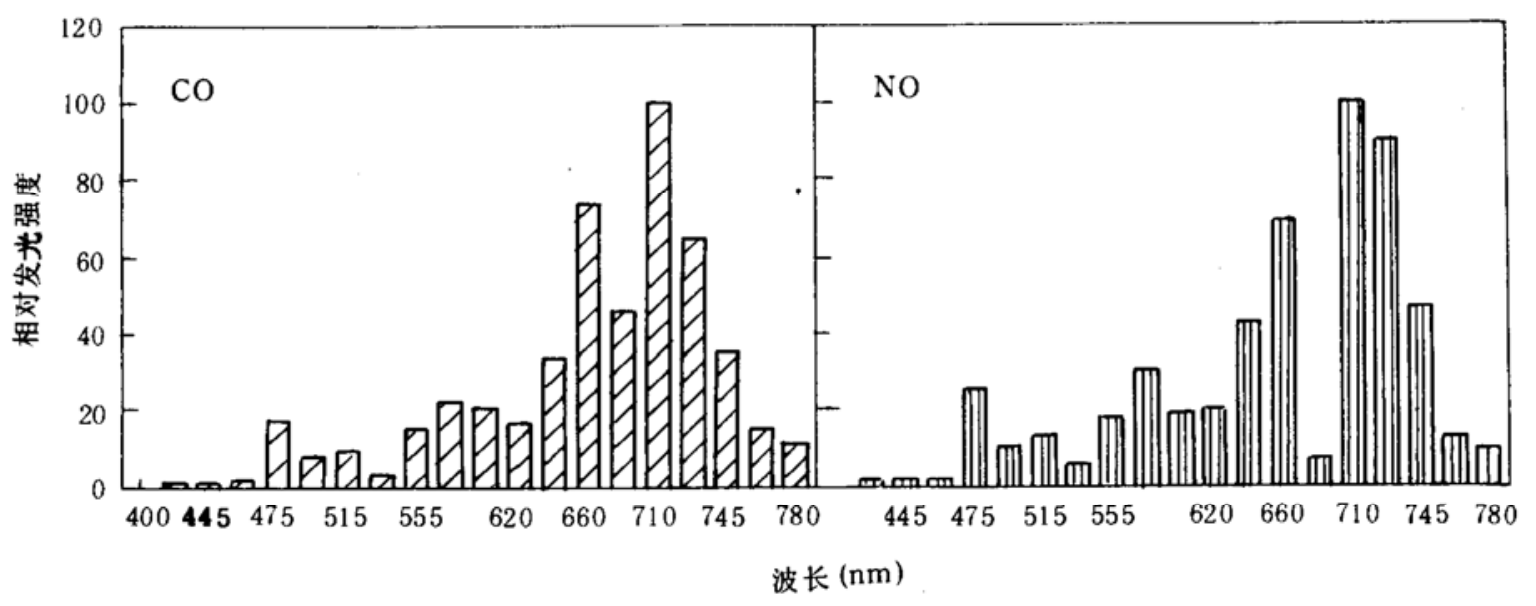

(a)

(b)

图 2 经 $\mathrm{CO}$ 和 NO 熏气后毛白杨叶片的发射光谱

(a) 以 $\mathrm{CO}$ 黑气, (b) 以 NO 黑气 
极易氧化, 故实验时以 $\mathrm{NO}$ 为代表研究 $\mathrm{NO}_{x}$ 对叶片作用, 示在图 2(b). 10 次重复试验结果表明, 像 CO 的作用规律一样, 经 $2 \%$ NO 熏气试验其叶片的 LCL 发射光谱未发生明显变化. 当 3 种气体以等浓度配比熏气 $1 \mathrm{~h}$ 后, 大多数毛白杨叶片已经脱落、坏死. 由于发光值极其低下, 很难测出其发射光谱变化.

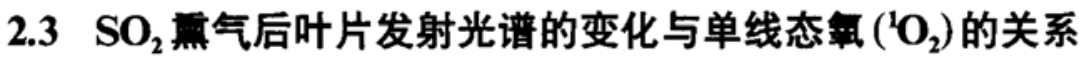

无论动物、植物和微生物体, 它们的低水平化学发光在体内的主要光子源是单线态氧 $\left({ }^{1} \mathrm{O}_{2}\right)$. 由于 $\mathrm{NaN}_{3}$ 可选择性猝灭由 ${ }^{1} \mathrm{O}_{2}$ 形成的光, 故利用该猝灭现象可以证实 ${ }^{1} \mathrm{O}_{2}$ 是否在反应体系中 存在. 图 3 示出几个不同波长经 $\mathrm{NaN}_{3}$ 处理后毛白杨叶片的发光随时间变化的规律. 由图 可知, 叶片虽经 $2 \% \mathrm{SO}_{2}$ 的相同的熏气试验, 但不同波长呈现不同的变化:

(a) 对照组 (未经 $\mathrm{SO}_{2}$ 熏气) 叶片的发光强度在所测定波段, 基本上成准指数规律下降. 虽 然在 575 和 $620 \mathrm{~nm}$ 在前 $30 \mathrm{~min}$ 内发光值出现稍许弛豫后又以准指数形式降低;

(b) 经过 $\mathrm{SO}_{2}$ 熏气的叶片显示不同的变化: 一种如图 3 曲线 (c) 和 (d), 叶片发光强度虽经 $\mathrm{NaN}_{3}$ 猝灭, 但发光强度在 $150 \mathrm{~min}$ 期间持续不变; 一种如图 3 曲线 (b), 在前 $60 \mathrm{~min}$ 发光强度
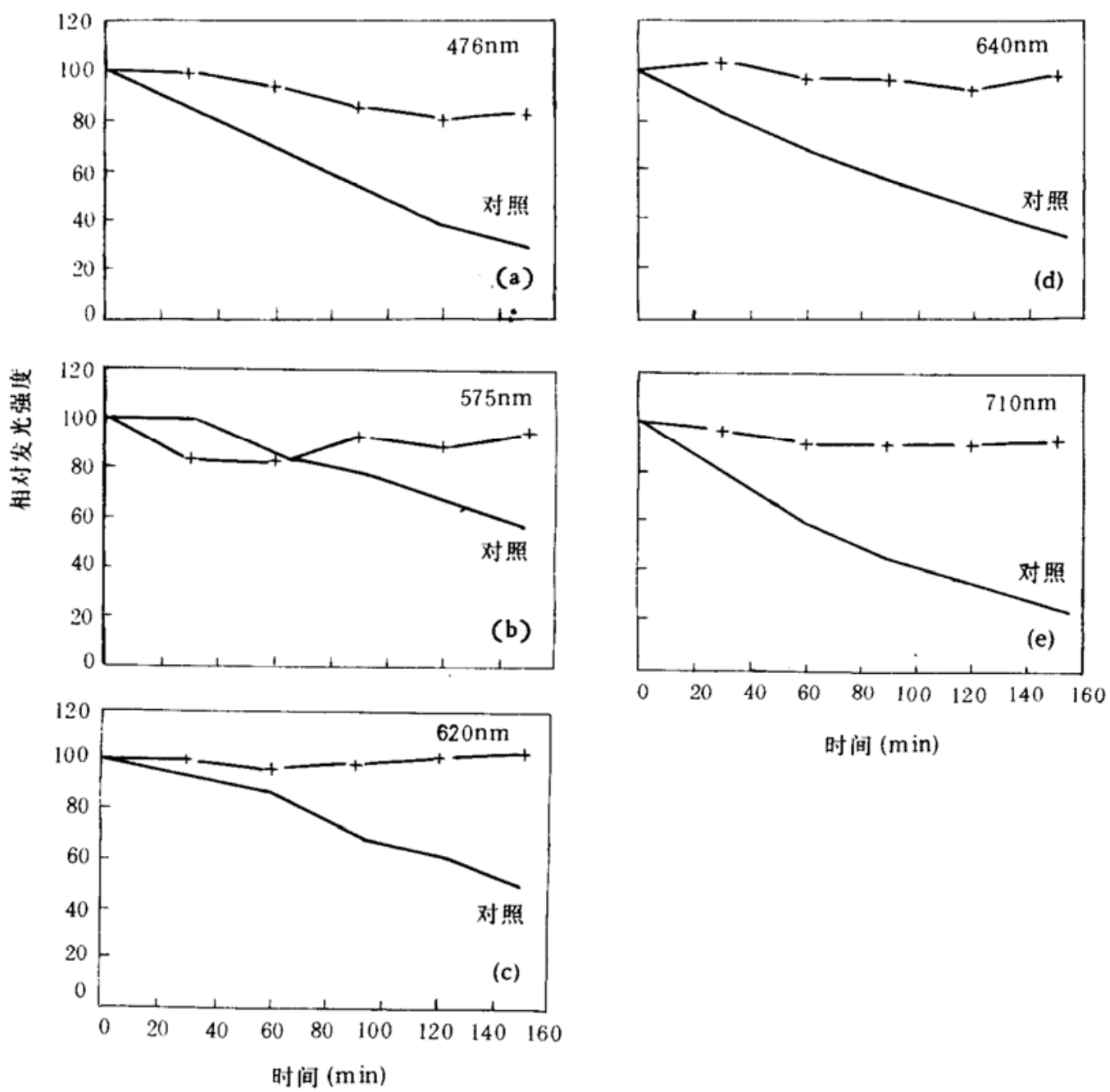

图 $32 \% \mathrm{SO}_{2}$ 熏气后叶片用 $1 \mathrm{mg} / \mathrm{ml} \mathrm{NaN}_{3}$ 浸泡 $10 \mathrm{~min}$, 随后在几个 ((a), (b), (c), (d), (e)) 选 定波长观测发光动力学曲线变化 
下降约 $20 \%$, 后又有所回升. 但仍较初始强度低 $10 \%$. 值得注意的是, 曲线 (a) 和 (e) 所展示 的发光强度是随着时间延迟缓慢下降. 其中曲线 (a) $(475 \mathrm{~nm})$ 在 $150 \mathrm{~min}$ 时发光值比初始强 度低 $20 \%$, 而曲线 (e) $(710 \mathrm{~nm})$ 则低 $10 \%$.

\section{4 毛白杨叶片经不同气体重气后, 475/710 比值的变化}

如图 4 所见, 对照组的叶片, 即在正常生理条件下 $475 / 710$ 两个波长处发光比值为 0.75 ; 经 $2 \% \mathrm{NO}$ 熏气 $1 \mathrm{~h}$ 后该比值上升到 1.1 , 而 $2 \% \mathrm{CO}$ 熏气 $1 \mathrm{~h}$ 升高到 0.85 . 与此不同, 经 $2 \% \mathrm{SO}_{2}$ 熏 气 $1 \mathrm{~h}$ 后的毛白杨叶片, 该比值增加到 3.5 , 相 当于对照组比值的 5 倍. 可以推想, 当测量 出所采叶片在 $475 / 710$ 处发光比值明显高于 正常值时, 自然联想到 $\mathrm{SO}_{2}$ 污染.

\section{3 讨 论}

生物系统的低水平化学发光其强度极 低, 一 般在 $10-10^{4}$ 光子 $/ \mathrm{cm}^{2} \cdot \mathrm{s}$ 的水平. 经 $\mathrm{SO}_{2}$ 熏气的毛白杨叶片的发光值是随着 $\mathrm{SO}_{2}$ 浓度的增加而降低. 通常叶片 $\mathrm{SO}_{2}$ 水平只有 几十个 ppm, 所产生的光子数量很少. 加之

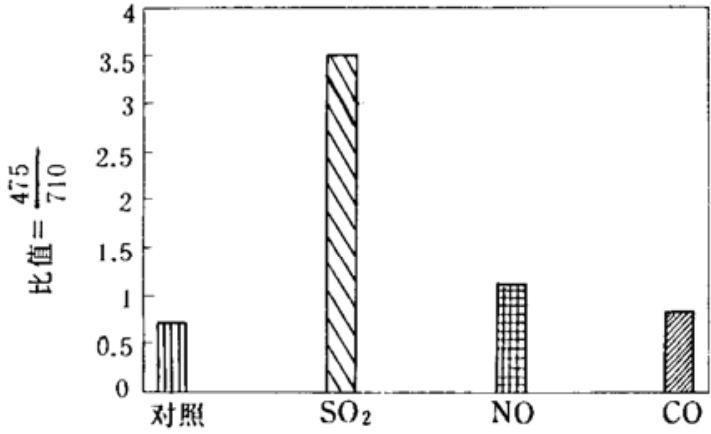

图 4 不同气体黒气后 $475 / 710$ 比值变化 光电倍增管对红光不敏感,给叶片的发射光谱分析带来一定困难. 但为了从复杂的气态环境 中鉴别出 $\mathrm{SO}_{2}$ 对叶片伤害作用, 除观察叶片光强度变化外, 光谱分析是不可缺少的重要环节. 为此, 实验选择叶片经 $2 \% \mathrm{SO}_{2}$ 熏气这样的特定条件下处理. 这时叶片的 LCL 已呈现枯死前 的 “闪光发射”, 发光强度上升一个数量级以上. 在这种条件下才得以进行发射光谱分析. 按照 Abeles 等人问的实验, 植物样品的发射光谱为一条宽的 Gaussion 分布曲线. 与我们测出毛白 杨叶片的发射光谱完全一致．光子发射主要分布在红光区,光子来源于下述反应:

(1) ${ }^{1} \mathrm{O}_{2}+{ }^{1} \mathrm{O}_{2} \rightarrow 2^{1} \mathrm{O}_{2}+\mathrm{hr}(575,640,703 \mathrm{~nm}) ;(2)^{1} \mathrm{O}_{2}$ 与双键分子反应生成激发态艎基 $\left(\mathrm{C}^{*}=\right.$ $\mathrm{O})$. 当 $\mathrm{C}^{*}=\mathrm{O}$ 退激时有光子发射 (460 nm 左右)；（3）活性氧基基团 $\left(\mathrm{O}_{\dot{2}}^{-},{ }^{\circ} \mathrm{OH}, \mathrm{H}_{2} \mathrm{O}_{2}, \mathrm{ROO}\right.$, $\mathrm{R}^{*}$ 等) 相互反应形成单线态氧发光.

毛白杨叶片受 $\mathrm{SO}_{2}$ 急性伤害时, 最大光峰 $710 \mathrm{~nm}$ 不变, 但出现 595,660 和 $760 \mathrm{~nm} 3$ 个光 峰. 从上述反应来看, $\mathrm{SO}_{2}$ 对叶片发射光谱的作用只是导致了红光区部分发光波段光子的重 新分配; 而在 $475 \mathrm{~nm}$ 发光局部增强估计和 $\mathrm{C}^{*}=\mathrm{O}$ 有关. 由 $\mathrm{SO}_{2}$ 诱发的叶片发射光谱变化, 找 出 475/710 波长处发光比值, 估计是从诸多气体污染因素中识别 $\mathrm{SO}_{2}$ 污染的一种颇有价值的 生物物理指标. 但要用之于监测实践, 尚需以伤害浓度的 $\mathrm{HF}, \mathrm{HCl}$ 或 $\mathrm{O}_{3}$ 进行对照检验的.

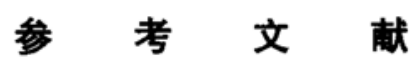

［1] 日本生态学会环境问题专门委员会编, 环境和指示生物 (陆地分册), 中国环境科学出版社, 1989.

[2]余叔文等, 大气污染伤害植物症状图谱, 上海科学技术出版社, 1981 .

[ 3] 郭世忠等, 环境科学, 1984, 5(6): 13-18.

[4]马 斌等, 科学通报, 1992, 37(24): 2270-2271.

[5] Ma Yu-qin et al., Bull. Environ. Contam. Toxicol., 1992, 49:906-913.

[6] Abcles, F. B., Ann. Rev. Plant Physiol., 1986, 3:49-72. 